\title{
Lack of association between circulating apelin level and frailty-related functional parameters in older adults: a cross-sectional study
}

II-Young Jang ${ }^{1 \dagger}$, Seungjoo Lee ${ }^{2 \dagger}$, Jeoung Hee Kim², Eunju Lee ${ }^{1}$, Jin Young Lee ${ }^{3}$, So Jeong Park ${ }^{3}$, Da Ae Kim³, Mark W. Hamrick ${ }^{4}$, Jin Hoon Park ${ }^{2^{*}}$ and Beom-Jun Kim ${ }^{5^{*}}$ (i)

\begin{abstract}
Background: Apelin, an active endogenous peptide, has been recently receiving great attention as a promising target for antiaging intervention, primarily based on results from genetically altered mice. To validate previous experimental data and investigate the possible role of apelin in humans, in this study, we examined serum apelin level in relation to frailty and its associated parameters in a cohort of ambulatory, community-dwelling older adults.

Methods: Blood samples were collected from 80 participants who underwent a comprehensive geriatric assessment, and apelin level was measured using an enzyme immunoassay kit. Phenotypic frailty and deficitaccumulation frailty index (FI) were assessed using widely validated approaches, proposed by Fried and Rockwood groups, respectively.

Results: After adjustment for sex, age, and body mass index, serum apelin level was found to be not significantly different according to phenotypic frailty status $(P=0.550)$ and not associated with $\mathrm{Fl}$, grip strength, gait speed, time to complete 5 chair stands, and muscle mass ( $P=0.433$ to 0.982). To determine whether the association between serum apelin level and frailty has a threshold effect, we divided the participants into quartiles according to serum apelin level. However, there were no differences in terms of frailty-related parameters and the risk for frailty among the quartile groups ( $P=0.248$ to 0.741$)$.
\end{abstract}

Conclusions: The serum apelin level was not associated with both phenotypic frailty and functional parameters in older adults, despite its beneficial effects against age-related physiologic decline in animal models. Further largescale longitudinal studies are necessary to understand the definite role of circulating apelin in frailty risk assessment.

Keywords: Apelin, Frailty, Aging, Sarcopenia, Biomarker

\footnotetext{
* Correspondence: jhpark@amc.seoul.kr; umkbj0825@amc.seoul.kr

${ }^{\dagger}$ II-Young Jang and Seungjoo Lee contributed equally to this work.

${ }^{2}$ Department of Neurological Surgery, Asan Medical Center, University of

Ulsan College of Medicine, 88 Olympic-ro 43-gil, Songpa-gu, Seoul 05505,

South Korea

${ }^{5}$ Division of Endocrinology and Metabolism, Department of Internal

Medicine, Asan Medical Center, University of Ulsan College of Medicine, 88

Olympic-ro 43-gil, Songpa-gu, Seoul 05505, South Korea

Full list of author information is available at the end of the article
}

C C The Author(s). 2020 Open Access This article is licensed under a Creative Commons Attribution 4.0 International License, which permits use, sharing, adaptation, distribution and reproduction in any medium or format, as long as you give appropriate credit to the original author(s) and the source, provide a link to the Creative Commons licence, and indicate if changes were made. The images or other third party material in this article are included in the article's Creative Commons licence, unless indicated otherwise in a credit line to the material. If material is not included in the article's Creative Commons licence and your intended use is not permitted by statutory regulation or exceeds the permitted use, you will need to obtain permission directly from the copyright holder. To view a copy of this licence, visit http://creativecommons.org/licenses/by/4.0/. The Creative Commons Public Domain Dedication waiver (http://creativecommons.org/publicdomain/zero/1.0/) applies to the data made available in this article, unless otherwise stated in a credit line to the data. 


\section{Background}

Frailty is a geriatric condition characterized by progressive physiologic decline across multiple body systems, leading to increased vulnerability to adverse outcomes and death [1]. Because the number of older persons is rapidly increasing worldwide, frailty is likely to become a significantly more serious public health concern. Despite the lack of gold standard measurement, two major frailty models have been well accepted and widely used in aging research and practice [2]. The first concept proposed by Fried et al. [3] is "physical frailty" that views frailty as a biologic syndrome of decreased reserve and resistance to stressors. The other concept proposed by Rockwood et al. [4] is "cumulative deficit frailty," which is also termed as "frailty index (FI)", based on the hypothesis that the accumulation of health, functional, psychological, and cognitive problems serves as an indicator of an individual's aging-related health status. Although each assessment tool has strengths and weaknesses in terms of clinical application [2], both are useful to identify older adults at high risk for mortality [5]. Importantly, frailty is a heterogeneous condition resulting from various causes that might be potentially reversible [6]. Therefore, continuous efforts to identify factors affecting functional changes with aging are critical to achieve the goal of expanding health span.

Apelin is an active endogenous peptide that acts via $G$ protein-coupled apelin receptor (APJ) to exert diverse functional effects [7]. This pleiotropic molecule is involved in multiple biologic processes, including cardiovascular regulation, neuroprotection, immunity, and glucose metabolism [8-10]. Apelin has been recently receiving great attention as a promising target for antiaging intervention, primarily based on results from genetically altered mice [11]. For example, the expression of apelin and APJ was downregulated in an agedependent manner $[12,13]$. Importantly, apelin-deficient mice exhibited accelerated the onset of sarcopenia and senescence, whereas apelin treatment in aged mice enhanced muscle strength and physical activity and rejuvenated behavioral and circadian phenotypes [12, 13]. However, despite the clear implications of apelin in physiologic alterations with aging, clinical studies relating circulating apelin concentration to frailty are limited. With the aim to validate previous in vitro and in vivo data and investigate the possible role of apelin in humans, this study examined serum apelin level in relation to frailty and its associated parameters in a cohort of older adults.

\section{Methods}

\section{Study design, setting, and participants}

This was a cross-sectional outpatient-based study. The study population comprised Koreans who had undergone a comprehensive geriatric assessment (CGA) at the Division of Geriatrics, Department of Internal Medicine, Asan Medical Center (AMC, Seoul, Korea), between July 2019 and April 2020. These participants had visited the clinic for the management of chronic diseases, such as hypertension, hyperlipidemia, and osteoarthritis, or for the evaluation of non-specific symptoms, such as fatigue and loss of appetite, which are frequently observed in older adults. They were ambulatory, community-dwelling, and not from nursing homes or inpatient facilities. Participants whose life expectancy was expected to be less than 1 year due to malignancy, symptomatic heart failure, or endstage renal failure were excluded. After the exclusion of ineligible participants, we collected blood samples from 80 eligible participants at the same visit when CGA was performed with their consent.

\section{Ethics statement}

This study was approved by the AMC Institutional Review Board (no. 2020-0259). Written informed consent was obtained from all enrolled participants. Ethical measures were in concordance with the Declaration of Helsinki.

\section{Comprehensive geriatric assessment}

All participants underwent a CGA by experienced nurses. Information on demographic characteristics and medical or surgical histories was collected through detailed interviews and reviews of medical records. We used measures from previously validated CGA-frailty index (CGA-FI) variables [14], including the geriatric domains of comorbidities; functional status; physical performance; nutritional status; and common geriatric syndromes, such as cognitive dysfunction, depression, or polypharmacy.

Multimorbidity was defined as having two or more of the 18 physician-diagnosed illnesses, namely, angina, atrial fibrillation/flutter, coronary artery disease, diabetes, heart failure, hypertension, myocardial infarction, peripheral vascular disease, stroke, anxiety disorder, arthritis, asthma, cancer within 5 years, chronic kidney disease (estimated glomerular filtration rate $<60$ ), chronic obstructive lung disease, degenerative spine disease, depression, and sensory impairment. Disability was defined as requiring assistance from another person to perform any of the seven activities of daily living (ADLs; feeding, dressing, grooming, walking, getting in and out of bed, toileting, and bathing or showering) or seven instrumental ADLs (IADLs) (making telephone calls, using transportation, shopping, cooking, doing housework, taking medications, and managing money). To assess social frailty, the 5-item social frailty questionnaire was administered: (1) going out less frequently, (2) rarely visiting the homes of friends, (3) feeling unhelpful to friends and family, (4) being alone, and (5) not talking 
with someone every day [15]. Cognitive dysfunction was defined as having less than 24 points on mini-mental status examination on selective participants identified as positive in the mini-cognitive screening test [16]. Depression was considered when the score of the 15-item Korean version of the short form of geriatric depression scale was 10 or more on selective participants identified as positive in the patient health questionnaire-2 (PHQ2) screening test [17].

\section{Functional status and sarcopenia assessment}

Handgrip strength of the dominant side was measured using Jamar hydraulic hand dynamometer (Patterson Medical, Warrenville, IL, USA) [18]. Participants were instructed to sit comfortably, bend their elbow at 90 degrees, and hold the dynamometer as strong as possible. The maximum value was adapted after all tests were conducted twice at intervals of 1 min or more. Usual gait speed (meters per second) from a 4-m walk and time to complete 5 chair stands (seconds) were measured [19]. The short physical performance battery (SPPB) comprises repeated chair stands, standing balance, and gait speed [20]. In the standing balance test, including sideby-side stance, semi-tandem stance, and tandem stance, the participants were instructed to stand for up to $10 \mathrm{~s}$. Ranging from 0 to 12 points, a higher SPPB score means better lower extremity function.

Body compositions including muscle mass (whole body lean body mass minus bone mineral content) were evaluated using a bioelectrical impedance analyzer (InBody S10; InBody, Seoul, Korea) with measuring frequencies of 1, 5, 50, 250,500 , and $1000 \mathrm{kHz}$ [21]. Participants were instructed to fast for $>8 \mathrm{~h}$ before the examination to minimize the possible effects of food and water intake. Appendicular skeletal muscle mass (ASM) was calculated as the sum of the muscle mass of both arms and legs, and ASM index (ASMI) was defined as adjusting the ASM to the height squared for an objective comparison of muscle mass between participants [22]. Finally, sarcopenia was diagnosed using the 2019 Consensus Guidelines from the Asian Working Group for Sarcopenia [23]. Briefly, older patients with low muscle mass (ASMI < $7.0 \mathrm{~kg} / \mathrm{m}^{2}$ in men, $<5.7 \mathrm{~kg} / \mathrm{m}^{2}$ in women) and low muscle strength (handgrip strength $<28 \mathrm{~kg}$ in men, $<18 \mathrm{~kg}$ in women) and/or low physical performance (gait speed $<1.0$ $\mathrm{m} / \mathrm{s}$, 5 -time chair stand test $\geq 12 \mathrm{~s}$, or SPPB score $\leq 9$ points) were classified as having sarcopenia.

\section{Frailty assessment}

1) Phenotypic frailty: Frailty was evaluated according to the Cardiovascular Health Study frailty criteria, a widely validated definition for frailty, proposed by Fried et al. [3]. The frailty phenotype scale was calculated by assigning 1 point to each of the five components that are relevant to an individual [24]: self-reported exhaustion determined by PHQ- 2 with a total score $>2$, low physical activity defined as weekly activity amount $<494.65 \mathrm{kcal}$ for men and $<283.50 \mathrm{kcal}$ for women using the International Physical Activity Questionnaire (IPAQ), weakness determined by the grip strength of the lowest quintile corresponding to sex and body mass index (BMI), slowness determined by the gait speed of the lowest quintile corresponding to sex and height, and unintentional weight loss $>4.5 \mathrm{~kg}$ in the past 12 months. How these assessments were performed in our study has been previously described [24]. Based on the total score, individuals were classified as robust ( 0 points), prefrail (1-2 points), or frail (3-5 points).

2) Deficit-accumulation frailty index (FI): The FI is known as the most sensitive predictor of adverse health outcomes and is based on the cumulative effect of medical, functional, and psychosocial age-related deficits, proposed by Rockwood et al. [4]. In this study, we calculated a FI that has been validated in other studies (see the complete list of assessed items in Supplementary Material) [2, 14]. The ratio between the number of identified deficits and 50 evaluable items is calculated from 0 to 1 , indicating that the higher the FI, the greater the frailty status.

\section{Measurement of apelin in human serum}

Blood samples were collected from the antecubital vein of each participant in the morning after an overnight fast of at least $8 \mathrm{~h}$. After sample centrifugation at $3000 \mathrm{rpm}$ for $5 \mathrm{~min}$ at $4{ }^{\circ} \mathrm{C}$, we carefully collected the supernatants to exclude cell components. All samples with hemolysis or clotting were discarded. The serum samples were stored at $-80^{\circ} \mathrm{C}$ prior to the determination of concentrations. Serum apelin concentration was measured using a previously validated nonselective apelin-12 enzyme immunoassay kit that recognizes the C-terminal sequence of 12 amino acids shared among all apelin isoforms (Phoenix Pharmaceuticals, Belmont, CA, USA) $[13,25]$. The lower limit of detection of the kit was 0.07 $\mathrm{ng} / \mathrm{mL}$, and the intra- and inter-assay coefficients of variation were less than 10 and 15\%, respectively.

\section{Sample size estimation}

In this study, we determined the sample size in accordance with the observations from previous human studies. Because of the limited clinical data on serum apelin levels according to the frailty spectrum, we used previously available data on serum apelin levels in diabetic patients [mean, 0.68; standard deviation (SD), 0.40; $n=$ 228] and non-diabetic patients (mean, 0.44; SD, 0.29; $n=162$ ) [26]. Although direct comparison between diabetes and frailty might be inappropriate, we performed this comparison considering that diabetes is one of the known phenotypes associated with metabolic aging. The 
required sample size for each group, with an alpha of 0.05 and a beta of 0.80 , was 23 if the frailty spectrum was classified into two groups. Similarly, a study measuring serum apelin levels in non-sarcopenic and sarcopenic patients showed significant between-group differences in apelin levels in 61 people [13]; however, these data could not be used in power calculations because of the lack of information on SD. As the frailty spectrum is continuous in terms of the FI and frailty is commonly classified into three groups according to frailty phenotype, we predetermined that a study population of 80 would be sufficient to assess serum apelin levels according to frailty status.

\section{Statistical analyses}

All data are presented as means \pm standard deviation or as numbers and percentages, unless otherwise specified. Baseline characteristics of the study participants according to phenotypic frailty status were compared using the analysis of variance with post-hoc analysis via Tukey's honest significance test for continuous variables and Fisher's exact tests for categorical variables. The estimated means with 95\% confidence intervals in serum apelin level according to the phenotypic frailty status and in frailty-related parameters according to serum apelin quartiles were generated and compared using analysis of covariance before and after adjustment for sex, age, and body mass index (BMI). The association between serum apelin level and frailty-related parameters was investigated using the linear regression analysis. To generate the odds ratio (OR) for phenotypic frailty according to serum apelin quartiles, logistic regression analysis was performed. All statistical analyses were performed using the Statistical Package for the Social Sciences (SPSS) version 18.0 (SPSS Inc., Chicago, IL, USA). $P<0.05$ was considered statistically significant.

\section{Results}

Baseline characteristics of 80 study participants are listed in Table 1. Among the $21(26.2 \%)$ robust, 47 (58.8\%) prefrail, and $12(15.0 \%)$ frail older adults based on Fried's criteria, 8 (38.1\%), 28 (59.6\%), and 7 (58.3\%) were women, respectively. The mean ages of the robust, prefrail, and frail groups were $67.5 \pm 6.5,69.7 \pm 6.2$, and $70.8 \pm 5.0$, respectively. There were no significant differences in weight, height, BMI, serum albumin level, time to complete 5 chair stands, ASMI, and prevalence of polypharmacy, multimorbidity, and ADL disability among the three groups. Frail participants had lower grip strength, gait speed, SPPB score, muscle mass, and mini-cognitive score and higher FI, social frailty score, and PHQ-2 score than robust and/or prefrail participants. Furthermore, frail participants were more likely to have sarcopenia, IADL disability, cognitive dysfunction, and depression than robust and/or prefrail participants.

Differences in serum apelin level according to the phenotypic frailty status were assessed using analysis of covariance. Before and after adjustment for sex, age, and BMI, there were no significant differences in serum apelin level between the three groups (Fig. 1).

Linear regression analyses were performed to examine the association between serum apelin level and frailtyrelated parameters with normal distribution (Table 2). However, serum apelin concentration was not associated with FI, grip strength, gait speed, time to complete 5 chair stands, muscle mass, and ASMI, regardless of the adjustment models.

To determine whether the association between serum apelin level and frailty-related parameters may have a threshold effect rather than a gradual effect, we divided the participants into quartiles according to serum apelin level (Fig. 2). Before and after adjustment for sex, age, and BMI, the groups did not differ significantly in terms of FI, grip strength, gait speed, time to complete 5 chair stands, SPPB score, muscle mass, ASMI, social frailty score, mini-cognitive score, and PHQ-2 score. Furthermore, logistic regression analyses showed that the ORs for phenotypic frailty according to serum apelin quartiles were not statistically significant, regardless of the adjustment models (Fig. 3).

\section{Discussion}

In a cohort of ambulatory, community-dwelling older adults, we observed that serum apelin level was not significantly associated with both the phenotypic frailty and the functional parameters. Additionally, serum apelin level was not associated with the risk of phenotypic frailty before and after adjustment for sex, age, and BMI.

Many lines of evidence from in vitro and animal experiments indicate that apelin may be implicated in various age-related disorders. While mice lacking apelin and its receptor showed markedly decreased muscle strength and physical performance, chronic apelin supplementation attenuated muscle aging $[8,13]$. The beneficial effects of apelin on muscle metabolism are probably mediated by the stimulation of AMP-activated protein kinase and Akt and the resultant mitochondriogenesis $[13,27]$. Downregulation of apelin in mice exhibited age-dependent decline in multiple organs, whereas systemic restoration of apelin improved cognitive and cardiovascular dysfunction, resulting in increased mammalian health span $[8,9,11,12,28]$. Because these physiologic alterations including musculoskeletal weakness and neurodegeneration are major manifestations of frailty, apelin could be expected not only as a therapeutic target to slow or reverse aging process but also as a clinical biomarker to assess the frailty status. 
Table 1 Baseline characteristics of the study participants according to phenotypic frailty status

\begin{tabular}{|c|c|c|c|c|}
\hline Variables & $\begin{array}{l}\text { Robust } \\
(n=21)\end{array}$ & $\begin{array}{l}\text { Prefrail } \\
(n=47)\end{array}$ & $\begin{array}{l}\text { Frail } \\
(n=12)\end{array}$ & $P$ \\
\hline Sex, no. (\%) & & & & 0.245 \\
\hline Female & $8(38.1)$ & $28(59.6)$ & $7(58.3)$ & \\
\hline Male & $13(61.9)$ & 19 (40.4) & $5(41.7)$ & \\
\hline Age (years) & $67.5 \pm 6.5$ & $69.7 \pm 6.2$ & $70.8 \pm 5.0$ & 0.257 \\
\hline Weight (kg) & $71.7 \pm 11.3$ & $67.3 \pm 10.2$ & $63.3 \pm 8.6$ & 0.069 \\
\hline Height (cm) & $161.7 \pm 10.0$ & $158.9 \pm 8.7$ & $157.2 \pm 5.6$ & 0.313 \\
\hline Body mass index $\left(\mathrm{kg} / \mathrm{m}^{2}\right)$ & $27.4 \pm 3.2$ & $26.6 \pm 3.0$ & $25.7 \pm 3.8$ & 0.297 \\
\hline Serum albumin (g/dL) & $3.83 \pm 0.36$ & $3.84 \pm 0.28$ & $3.73 \pm 0.25$ & 0.559 \\
\hline Frailty index (range, $0-1)$ & $0.070 \pm 0.035$ & $0.126 \pm 0.063^{*}$ & $0.230 \pm 0.115^{*, \dagger}$ & $<0.001$ \\
\hline Grip strength (kg) & $32.7 \pm 7.8$ & $27.9 \pm 8.9$ & $20.9 \pm 6.6^{*,+}$ & 0.001 \\
\hline Gait speed (m/s) & $1.21 \pm 0.18$ & $1.03 \pm 0.33$ & $0.75 \pm 0.28^{*},+$ & $<0.001$ \\
\hline Chair stand (s) & $9.6 \pm 4.2$ & $11.3 \pm 8.2$ & $14.5 \pm 7.2$ & 0.193 \\
\hline SPPB score (range, 0-12) & $11.5 \pm 1.0$ & $10.3 \pm 2.7$ & $9.5 \pm 2.2^{*}$ & 0.046 \\
\hline Muscle mass (kg) & $25.3 \pm 4.9$ & $22.5 \pm 5.6$ & $20.0 \pm 3.6^{*}$ & 0.021 \\
\hline ASMI $\left(\mathrm{kg} / \mathrm{m}^{2}\right)$ & $7.29 \pm 1.26$ & $6.78 \pm 1.26$ & $6.23 \pm 0.99$ & 0.065 \\
\hline Sarcopenia, no. (\%) & $0(0.0)$ & $7(14.9)$ & $5(41.7)$ & 0.006 \\
\hline Use of $\geq 5$ prescription drugs, no. (\%) & $8(38.1 \%)$ & $23(48.9)$ & $8(66.7)$ & 0.287 \\
\hline Multimorbidity, no. (\%) & $15(71.4)$ & $35(74.5)$ & $11(91.7)$ & 0.382 \\
\hline ADL disability, no. (\%) & $0(0.0)$ & $3(6.4)$ & $2(16.7)$ & 0.163 \\
\hline IADL disability, no. (\%) & $1(4.8)$ & 15 (31.9) & $8(66.7)$ & 0.001 \\
\hline Social frailty score (range, $0-5$ ) & $0.95 \pm 0.67$ & $1.40 \pm 1.10$ & $2.08 \pm 1.00^{*}$ & 0.009 \\
\hline Mini-Cognition score (range, 0-5) & $4.33 \pm 0.86$ & $3.64 \pm 1.24$ & $3.27 \pm 1.27^{*}$ & 0.026 \\
\hline Cognitive dysfunction, no. (\%) & $0(0.0)$ & $3(6.4)$ & $4(33.3)$ & 0.003 \\
\hline PHQ-2 score (range, 0-6) & $0.86 \pm 0.85$ & $1.45 \pm 1.94$ & $3.82 \pm 1.72^{*,+}$ & $<0.001$ \\
\hline Depression, no. (\%) & $0(0.0)$ & $5(10.6)$ & $8(66.7)$ & $<0.001$ \\
\hline
\end{tabular}

Values are presented as the mean \pm standard deviation unless otherwise specified. Bold means that values are statistically significant. Comparisons between the three groups were investigated using the analysis of variance with post-hoc analysis via Tukey's honest significance test for continuous variables and Fisher's exact tests for categorical variables. ${ }^{*}$ and $\dagger$ indicate statistically significant differences of continuous variables from the robust and prefrail groups, respectively. $S P P B$ short physical performance battery, $A S M I$ appendicular skeletal muscle mass index, $A D L$ activity of daily living, IADL instrumental activity of daily living, $P H Q-2$ patient health questionnaire-2

\section{A Unadjusted}

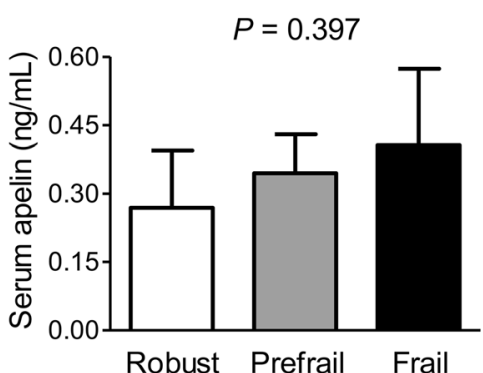

B Sex, age, and BMI adjusted

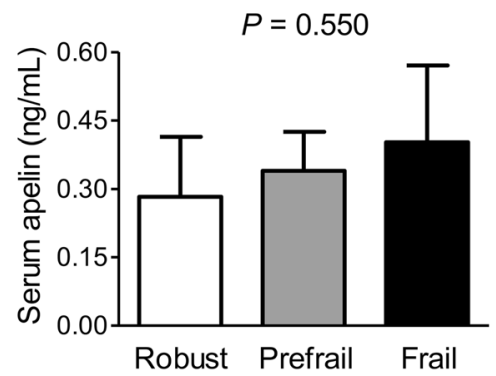

Fig. 1 Differences in serum apelin levels according to the phenotypic frailty status (a) before and (b) after adjustment for sex, age, and BMI. The estimated means with $95 \%$ confidence intervals were generated and compared using analysis of covariance. BMl, body mass index 
Table 2 Linear regression analyses to determine the association between serum apelin level and frailty-related parameters

\begin{tabular}{|c|c|c|c|c|c|c|c|c|}
\hline & \multicolumn{4}{|c|}{ Unadjusted } & \multicolumn{4}{|c|}{ Sex, age, and BMI adjusted } \\
\hline & $\beta$ & SE & $\beta$ & $P$ & $\beta$ & SE & $\beta$ & $P$ \\
\hline Frailty index & 0.022 & 0.032 & 0.076 & 0.503 & 0.017 & 0.031 & 0.058 & 0.598 \\
\hline Grip strength & -4.825 & 3.462 & -0.157 & 0.167 & -0.558 & 2.183 & -0.018 & 0.799 \\
\hline Gait speed & -0.153 & 0.123 & -0.142 & 0.216 & -0.093 & 0.118 & -0.086 & 0.433 \\
\hline Chair stand & -1.181 & 2.842 & -0.048 & 0.679 & -2.134 & 2.811 & -0.086 & 0.450 \\
\hline Muscle mass & -3.102 & 2.073 & -0.168 & 0.139 & 0.025 & 1.081 & 0.001 & 0.982 \\
\hline ASMI & -0.645 & 0.486 & -0.150 & 0.189 & 0.051 & 0.330 & 0.012 & 0.876 \\
\hline
\end{tabular}

The Enter method was applied to this model. Bold means that values are statistically significant. $\beta$ unstandardized regression coefficient, SE standard error, $\beta$ standardized regression coefficient, $B M I$ body mass index, $A S M I$ appendicular skeletal muscle mass index

\section{A Unadjusted}
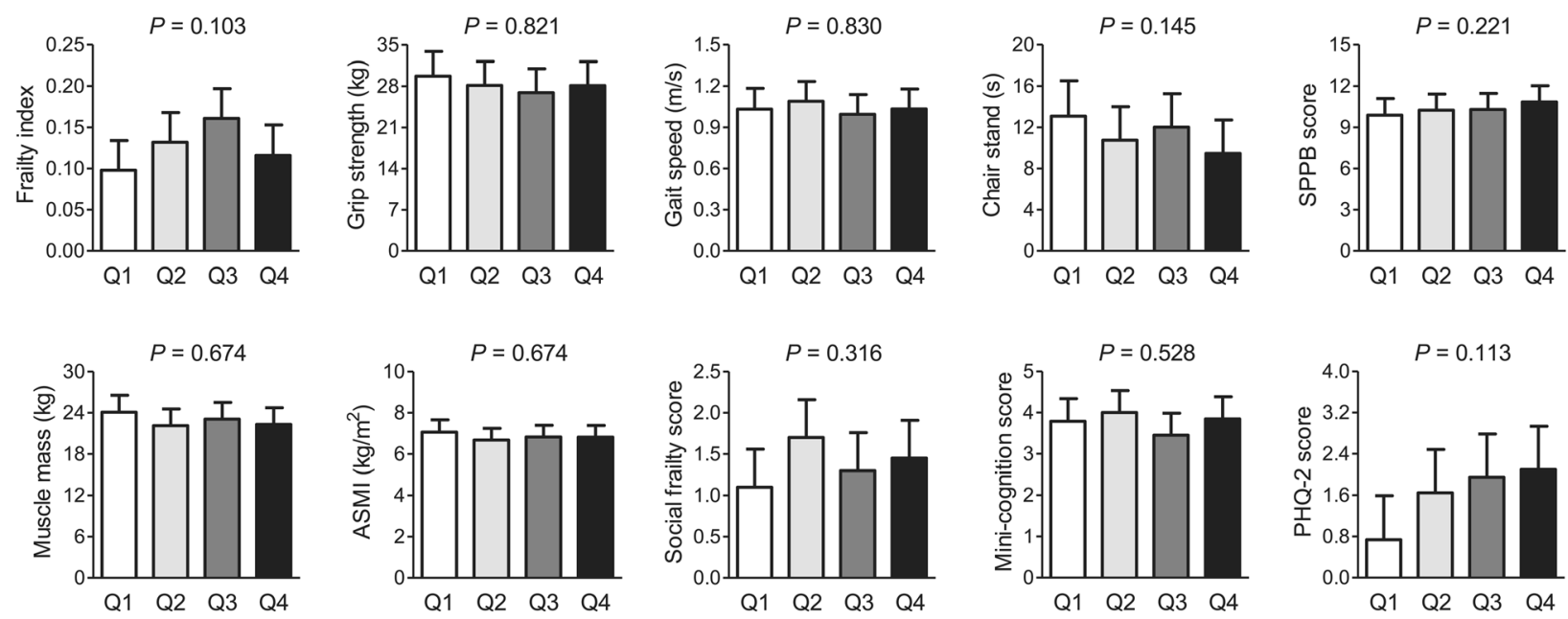

B Sex, age, and BMI adjusted
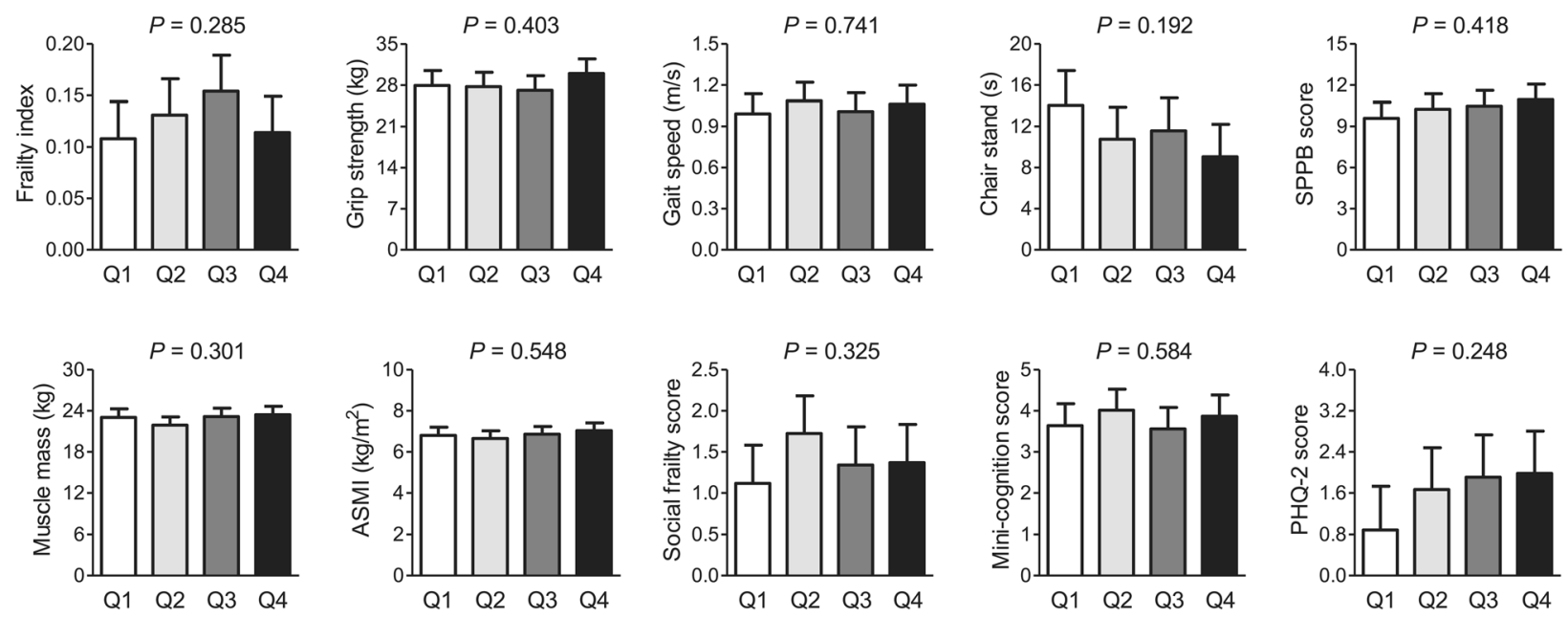

Fig. 2 Differences in frailty-related parameters according to serum apelin quartiles (a) before and (b) after adjustment for sex, age, and BMI. The estimated means with $95 \%$ confidence intervals were generated and compared using analysis of covariance. Serum apelin quartiles: Q1 = $0.087-0.199$ $\mathrm{ng} / \mathrm{mL}, \mathrm{Q} 2=0.200-0.269 \mathrm{ng} / \mathrm{mL}$, Q3 $=0.270-0.378 \mathrm{ng} / \mathrm{mL}$, and Q4 = 0.379-2.440 ng $/ \mathrm{mL}$. BMl, body mass index; SPPB, short physical performance battery; ASMI, appendicular skeletal muscle mass index; PHQ-2, patient health questionnaire-2 
A Unadjusted

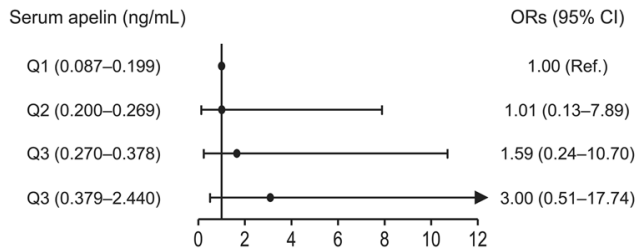

B Sex, age, and BMl adjusted

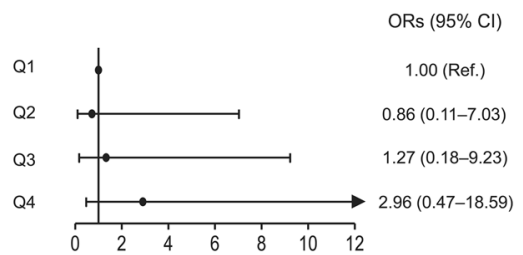

Fig. 3 Logistic regression analyses to determine the odds ratios for phenotypic frailty according to serum apelin quartiles (a) before and (b) after adjustment for sex, age, and BMI. BMI, body mass index; OR, odds ratio; $\mathrm{Cl}$, confidence interval

Despite the definite role and plausible mechanisms of apelin as an antiaging factor in animal models, its effects on human health remain unclear. Because it is impossible to conduct interventional trials in humans without safety verification from preclinical data, the roles of candidate factors on human metabolism must be extrapolated from the observational results, leading us to conduct this clinical study. However, different from the experimental results, we did not observe a significant association between circulating apelin level and frailtyrelated parameters in older adults. Although we cannot determine the exact reason for this discrepancy, several explanations might be hypothesized. First, although mice are widely used to study human illness mechanisms because of biologic similarity, they are not the same. In detail, the comparison research focusing on the genetic and biochemical processes regulating genome activity in humans and mice by the Mouse ENCODE Consortium revealed a large degree of divergence of sequences involved in transcriptional regulation, chromatin state, and higher-order chromatin organization [29, 30]. This could answer the question why certain processes and systems in mice, such as the immune system, metabolism, and stress response, are significantly different to those in humans and why drugs that have worked in animal experiments are not equally successful in humans. The lack of associations between apelin and frailty in humans, unlike in mice, could also be attributable to these differences in two mammals. Second, physiologic apelin level observed in humans may not be high enough to exert the phenotypic changes. The apelin expression and production are almost completely blocked in apelindeficient mice, and the concentration of apelin treated into mice is relatively high with a long period [12, 13]. On the contrary, because the difference in apelin mean values between the lowest (Q1) and highest (Q4) quartiles in our study was only $0.466 \mathrm{ng} / \mathrm{mL}$, we may have not observed significant changes of functional parameters. Third, apelin is synthesized as a 77-residue preproapelin and cleaved into the 55-residue proapelin and subsequently into 13-36-residue active isoforms [31]. Therefore, diverse isoforms, such as apelin-13, apelin-17, and apelin-36, could be present in biological fluids, including blood, and there is a possibility that each isoform plays a different role as a biomarker to assess frailty. This issue needs to be clarified through further studies using more accurate techniques.

The major strengths of our study are that we adapted both frailty operational definitions that have been well validated and included various functional parameters, including grip strength, gait speed, time to complete 5 chair stands, SPPB score, social frailty score, mini-cognitive score, PHQ-2 score, as well as muscle mass, contributing to increased reliability of our results. However, despite these strengths, several limitations should also be considered when interpreting the results. First, because this was a crosssectional study, we could not determine a causal relationship between the variables. Second, because of difficulties in simultaneously obtaining the information about frailty status and the blood samples, the number of enrolled participants with consent was relatively small. However, we believe that this preliminary analysis might provide an important background for further studies. Third, our study population was exclusively Koreans. Thus, we cannot be certain that our results are applicable to other populations. Fourth, we could not adjust for various confounding factors because of a relatively small sample size in the analysis. Finally, we cannot exclude the possibility that any biased information or uncontrolled factors that affect apelin and frailty could affect the conclusion.

\section{Conclusion}

In summary, serum apelin levels did not differ significantly according to the phenotypic frailty status and was not associated with FI and functional parameters in older adults, despite the beneficial effects of apelin against age-related physiologic decline that is observed primarily in animal models. Additional welldesigned large-scale longitudinal studies are necessary to understand the definite role of circulating apelin in frailty risk assessment. 


\section{Supplementary information}

Supplementary information accompanies this paper at https://doi.org/10. 1186/s12877-020-01837-9.

\section{Additional file 1}

\section{Abbreviations}

FI: Frailty index; APJ: G protein-coupled apelin receptor; CGA: Comprehensive geriatric assessment; AMC: Asan Medical Center; ADL: Activity of daily living; IADL: Instrumental activity of daily living; PHQ-2: Patient health questionnaire-2; SPPB: Short physical performance battery;

ASM: Appendicular skeletal muscle mass; ASMI: Appendicular skeletal muscle mass index; BMl: Body mass index; OR: Odds ratio

\section{Acknowledgements}

Not applicable.

\section{Authors' contributions}

Study design: IJ, JHP, BK. Data acquisition: SL, JHK, JYL, SJP, DAK. Data analysis and interpretation: IJ, SL, EL, MWH, BK. Drafting of manuscript: IJ, SL, $\mathrm{MWH}, J \mathrm{HP}, \mathrm{BK}$. All authors have read and agreed to the final version of manuscript.

\section{Funding}

This study was supported by grants from the National Research Foundation of Korea, funded by the South Korean government, MSIT

(2019R1A2C2006527), from the Asan Institute for Life Science, AMC, Seoul, South Korea (2020IF0008), and from the Korea Health Technology R\&D Project through the Korea Health Industry Development Institute (KHIDI), funded by the Ministry of Health \& Welfare, South Korea (HI18C2383). The funders had no role in study design, data collection and analysis, decision to publish, or preparation of the manuscript.

\section{Availability of data and materials}

The datasets used and/or analysed during the current study are available from the corresponding author on reasonable request.

\section{Ethics approval and consent to participate}

This study was approved by the Asan Medical Center Institutional Review Board (no. 2020-0259). Written informed consent was obtained from all enrolled participants.

\section{Consent for publication}

Not applicable.

\section{Competing interests}

The authors declare no conflicts of interest.

\section{Author details}

'Division of Geriatrics, Department of Internal Medicine, Asan Medical Center, University of Ulsan College of Medicine, Seoul, South Korea. ${ }^{2}$ Department of Neurological Surgery, Asan Medical Center, University of Ulsan College of Medicine, 88 Olympic-ro 43-gil, Songpa-gu, Seoul 05505, South Korea. ${ }^{3}$ Asan Institute for Life Sciences, Asan Medical Center, University of Ulsan College of Medicine, Seoul, South Korea. ${ }^{4}$ Department of Cell Biology and Anatomy, Medical College of Georgia, Augusta University, Augusta, GA, USA. ${ }^{5}$ Division of Endocrinology and Metabolism, Department of Internal Medicine, Asan Medical Center, University of Ulsan College of Medicine, 88 Olympic-ro 43-gil, Songpa-gu, Seoul 05505, South Korea.

\section{Received: 5 June 2020 Accepted: 15 October 2020}

\section{Published online: 21 October 2020}

\section{References}

1. Clegg A, Hassan-Smith Z. Frailty and the endocrine system. Lancet Diabetes Endocrinol. 2018;6(9):743-52 https://doi.org/10.1016/s2213-8587(18)30110-4.

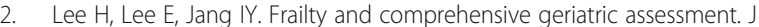
Korean Med Sci. 2020;35(3):e16 https://doi.org/10.3346/jkms.2020.35.e16.

3. Fried LP, Tangen CM, Walston J, Newman AB, Hirsch C, Gottdiener J, Seeman T, Tracy R, Kop WJ, Burke G, McBurnie MA. Frailty in older adults: evidence for a phenotype. J Gerontol A Biol Sci Med Sci. 2001;56(3):M14656 https://doi.org/10.1093/gerona/56.3.m146.

4. Rockwood K, Mitnitski A. Frailty in relation to the accumulation of deficits. J Gerontol A Biol Sci Med Sci. 2007;62(7):722-7 https://doi.org/10.1093/ gerona/62.7.722

5. Walston J, Bandeen-Roche K, Buta B, Bergman H, Gill TM, Morley JE, Fried LP, Robinson TN, Afilalo J, Newman AB, López-Otín C, De Cabo R, Theou O, et al. Moving frailty toward clinical practice: NIA intramural frailty science symposium summary. J Am Geriatr Soc. 2019;67(8):1559-64 https://doi.org/ 10.1111/jgs.15928

6. Clegg A, Young J, lliffe S, Rikkert MO, Rockwood K. Frailty in elderly people. Lancet. 2013;381(9868):752-62 https://doi.org/10.1016/S01406736(12)62167-9.

7. Lee DK, Cheng R, Nguyen T, Fan T, Kariyawasam AP, Liu Y, Osmond DH, George SR, O'Dowd BF. Characterization of apelin, the ligand for the APJ receptor. J Neurochem. 2000;74(1):34-41 https://doi.org/10.1046/j.1471-4159. 2000.0740034.x

8. Kwak SE, Cho SC, Bae JH, Lee J, Shin HE, Di Zhang D, Lee Yl, Song W. Effects of exercise-induced apelin on muscle function and cognitive function in aged mice. Exp Gerontol. 2019;127:110710 https://doi.org/10.1016/j.exger. 2019.110710.

9. Luo H, Han L, Xu J. Apelin/APJ system: a novel promising target for neurodegenerative diseases. J Cell Physiol. 2020;235(2):638-57 https://doi. org/10.1002/jcp.29001.

10. Kazemi F, Zahediasl S. Effects of exercise training on adipose tissue apelin expression in streptozotocin-nicotinamide induced diabetic rats. Gene. 2018; 662:97-102 https://doi.org/10.1016/j.gene.2018.04.003.

11. Zhou Q, Chen L, Tang M, Guo Y, Li L. Apelin/APJ system: A novel promising target for anti-aging intervention. Clin Chimica Acta Int J Clin Chem. 2018; 487:233-40 https://doi.org/10.1016/j.cca.2018.10.011.

12. Rai R, Ghosh AK, Eren M, Mackie AR, Levine DC, Kim SY, Cedernaes J, Ramirez V, Procissi D, Smith LH, Woodruff TK, Bass J, Vaughan DE. Downregulation of the Apelinergic Axis accelerates aging, whereas its systemic restoration improves the mammalian Healthspan. Cell Rep. 2017; 21(6):1471-80 https://doi.org/10.1016/j.celrep.2017.10.057.

13. Vinel C, Lukjanenko L, Batut A, Deleruyelle S, Pradère JP, Le Gonidec S, Dortignac A, Geoffre N, Pereira O, Karaz S, Lee U, Camus M, Chaoui K, et al. The exerkine apelin reverses age-associated sarcopenia. Nat Med. 2018;24(9): 1360-71 https://doi.org/10.1038/s41591-018-0131-6.

14. Kim DH, Afilalo J, Shi SM, Popma JJ, Khabbaz KR, Laham RJ, Grodstein F, Guibone K, Lux E, Lipsitz LA. Evaluation of changes in functional status in the year after aortic valve replacement. JAMA Intern Med. 2019;179(3):38391 https://doi.org/10.1001/jamainternmed.2018.6738.

15. Park H, Jang IY, Lee HY, Jung HW, Lee E, Kim DH. Screening Value of Social Frailty and Its Association with Physical Frailty and Disability in CommunityDwelling Older Koreans: Aging Study of PyeongChang Rural Area. Int J Environ Res Public Health. 2019:16(16) https://doi.org/10.3390/ ijerph16162809.

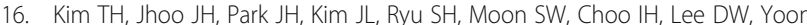
JC, Do YJ, Lee SB, Kim MD, Kim KW. Korean version of mini mental status examination for dementia screening and its' short form. Psychiatry Investig. 2010;7(2):102-8 https://doi.org/10.4306/pi.2010.7.2.102.

17. Kroenke K, Spitzer RL, Williams JB. The patient health Questionnaire-2: validity of a two-item depression screener. Med Care. 2003;41(11):1284-92 https://doi.org/10.1097/01.Mlr.0000093487.78664.3c.

18. Roberts HC, Denison HJ, Martin HJ, Patel HP, Syddall H, Cooper C, Sayer AA. A review of the measurement of grip strength in clinical and epidemiological studies: towards a standardised approach. Age Ageing. 2011;40(4):423-9 https://doi.org/10.1093/ageing/afr051.

19. Peel NM, Kuys SS, Klein K. Gait speed as a measure in geriatric assessment in clinical settings: a systematic review. J Gerontol A Biol Sci Med Sci. 2013; 68(1):39-46 https://doi.org/10.1093/gerona/gls174.

20. Jung HW, Roh H, Cho Y, Jeong J, Shin YS, Lim JY, Guralnik JM, Park J. Validation of a multi-sensor-based kiosk for short physical performance battery. J Am Geriatr Soc. 2019;67(12):2605-9 https://doi.org/10.1111/jgs.16135.

21. Oh JH, Song S, Rhee H, Lee SH, Kim DY, Choe JC, Ahn J, Park JS, Shin MJ, Jeon YK, Lee HW, Choi JH, Lee HC, et al. Normal reference plots for the bioelectrical impedance vector in healthy Korean adults. J Korean Med Sci. 2019;34(30):e198 https://doi.org/10.3346/jkms.2019.34.e198.

22. Jang IY, Jung HW, Lee CK, Yu SS, Lee YS, Lee E. Comparisons of predictive values of sarcopenia with different muscle mass indices in Korean rural 
older adults: a longitudinal analysis of the aging study of PyeongChang rural area. Clin Interv Aging. 2018;13:91-9 https://doi.org/10.2147/cia. S155619.

23. Chen LK, Woo J, Assantachai P, Auyeung TW, Chou MY, lijima K, Jang HC, Kang L, Kim M, Kim S, Kojima T, Kuzuya M, Lee JSW, et al. Asian Working Group for Sarcopenia: 2019 Consensus Update on Sarcopenia Diagnosis and Treatment. J Am Med Dir Assoc. 2020;21(3):300-7 e302. https://doi.org/ 10.1016/j.jamda.2019.12.012.

24. Won CW, Lee S, Kim J, Chon D, Kim S, Kim C-O, Kim MK, Cho B, Choi KM, Roh E, Jang HC, Son SJ, Lee J-H, et al. Korean frailty and aging cohort study (KFACS): cohort profile. BMJ Open. 2020;10(4):e035573 https://doi.org/10. 1136/bmjopen-2019-035573.

25. Son JS, Chae SA, Park BI, Du M, Song W. Plasma apelin levels in overweight/ obese adults following a single bout of exhaustive exercise: a preliminary cross-sectional study. Endocrinol Diabetes Nutr. 2019;66(5):278-90 https:// doi.org/10.1016/j.endinu.2018.12.005.

26. Habchi M, Duvillard L, Cottet V, Brindisi MC, Bouillet B, Beacco M, Crevisy E, Buffier P, Baillot-Rudoni S, Verges B, Petit JM. Circulating apelin is increased in patients with type 1 or type 2 diabetes and is associated with better glycaemic control. Clin Endocrinol. 2014;81(5):696-701 https://doi.org/10 1111/cen.12404.

27. Dray C, Knauf C, Daviaud D, Waget A, Boucher J, Buléon M, Cani PD, Attané C, Guigné C, Carpéné C, Burcelin R, Castan-Laurell I, Valet P. Apelin stimulates glucose utilization in normal and obese insulin-resistant mice. Cell Metab. 2008;8(5):437-45 https://doi.org/10.1016/j.cmet.2008.10.003.

28. Masoumi J, Abbasloui M, Parvan R, Mohammadnejad D, Pavon-Djavid G, Barzegari A, Abdolalizadeh J. Apelin, a promising target for Alzheimer disease prevention and treatment. Neuropeptides. 2018;70:76-86 https://doi. org/10.1016/j.npep.2018.05.008

29. Yue F, Cheng Y, Breschi A, Vierstra J, Wu W, Ryba T, Sandstrom R, Ma Z, Davis C, Pope BD, Shen Y, Pervouchine DD, Djebali S, et al. A comparative encyclopedia of DNA elements in the mouse genome. Nature. 2014; 515(7527):355-64 https://doi.org/10.1038/nature13992.

30. Brown JB, Celniker SE. Lessons from modENCODE. Annu Rev Genomics Hum Genet. 2015;16:31-53 https://doi.org/10.1146/annurev-genom-090413025448.

31. Kawamata Y, Habata Y, Fukusumi S, Hosoya M, Fujii R, Hinuma S, Nishizawa N, Kitada C, Onda H, Nishimura O, Fujino M. Molecular properties of apelin: tissue distribution and receptor binding. Biochim Biophys Acta. 2001; 1538(2-3):162-71 https://doi.org/10.1016/s0167-4889(00)00143-9.

\section{Publisher's Note}

Springer Nature remains neutral with regard to jurisdictional claims in published maps and institutional affiliations.

Ready to submit your research? Choose BMC and benefit from:

- fast, convenient online submission

- thorough peer review by experienced researchers in your field

- rapid publication on acceptance

- support for research data, including large and complex data types

- gold Open Access which fosters wider collaboration and increased citations

- maximum visibility for your research: over $100 \mathrm{M}$ website views per year

At BMC, research is always in progress.

Learn more biomedcentral.com/submissions 